\title{
DESARROLLO DE LÍDERES COMUNITARIAS EN TIEMPOS DE PANDEMIA
}

\author{
AUTORES: Yanay Rodríguez Cabrera ${ }^{1}$ \\ Berta Onelia Mezquía Noa ${ }^{2}$ \\ Inés Barbara Aguiar Márquez ${ }^{3}$
}

\section{DIRECCIÓN PARA CORRESPONDENCIA: (ines@uart.edu.cu)}

Fecha de recepción: 12/01/2021

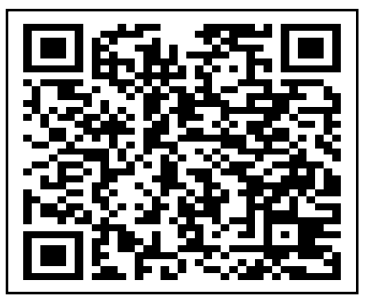

Fecha de aceptación: 20/08/2021

\section{RESUMEN}

El año 2020 impuso al mundo un reto sin precedentes: la pandemia Covid-19. El aislamiento físico como medida indispensable para detener la propagación del virus interrumpe las conexiones sociales, impone modificaciones a los hábitos y estilos de vida, de trabajo y de relación de las personas, con la aparición de los consecuentes estados de ansiedad y estrés que generan dichos cambios. El presente trabajo pretende socializar una experiencia comunitaria en el enfrentamiento a la covid-19, desarrollada en un asentamiento rural del municipio Caimito (provincia Artemisa) y sustentada en preceptos teóricos y metodológicos de la Investigación Acción-Participativa. El proyecto de intervención que se presenta se titula "Desde mi Casa" y promueve el desarrollo de líderes comunitarios para el diagnóstico y diseño ad hoc de acciones que, sin comprometer la salud de la comunidad, propician el bienestar psicosocial. Los beneficios de la propuesta se hacen evidentes en una comunidad que con escasos recursos materiales pero elevado sentido psicológico de comunidad, se mantiene libre de contagio y promueve el bienestar psicosocial de los convivientes. El presente trabajo persigue socializar una experiencia de apoyo psicosocial basado en la comunidad, mediante el desarrollo de actores sociales.

PALABRAS CLAVE: líderes comunitarias; apoyo psicosocial; investigación acciónparticipativa.

\section{DEVELOPMENT OF COMMUNITY LEADERS IN TIMES OF PANDEMIC}

\section{ABSTRACT}

The year 2020 imposed on the world an unprecedented challenge: the Covid-19 pandemic. Physical isolation as an essential measure to stop the spread of the virus interrupts social connections, imposes modifications to people's habits and lifestyles, work and relationships, with the appearance of the consequent states of anxiety and stress generated by said changes. The present work aims to socialize a community experience in coping with covid-19, developed in a rural settlement in the Caimito municipality (Artemisa province) and supported by theoretical and

\footnotetext{
${ }^{1}$ Prof. Asistente. Universidad de Artemisa. Cuba.

2 Profesora Auxiliar. Directora CUM Caimito Universidad de Artemisa. Cuba.

${ }^{3}$ Profesora Auxiliar. Universidad de Artemisa. Cuba.
} 
methodological precepts of Action-Participatory Research. The intervention project presented is entitled "From my House" and promotes the development of community leaders for the diagnosis and ad hoc design of actions that, without compromising the health of the community, promote psychosocial well-being. The benefits of the proposal are evident in a community that with scarce material resources but a high psychological sense of community, remains free from contagion and promotes the psychosocial well-being of the cohabitants. The present work seeks to socialize an experience of psychosocial support based on the community, through the development of social actors.

KEYWORDS: community leaders; psychosocial support; participatory action research.

\section{INTRODUCCIÓN}

Las últimas décadas, se han caracterizado por la ocurrencia de grandes desastres a escala mundial, tanto de origen natural como de origen tecnológico y sanitario. "La mayoría de los desastres que han podido ocurrir todavía no han tenido lugar” planteaba en el 2015 la Global Assessment Report on Disasters Risk Reduction (GAR). Para confirmarlo, el año 2020 impuso al mundo un reto sin precedentes: la pandemia generada por el SARSCOV-2, virus causante de la Covid-19. Sin lugar a dudas, un desastre con consecuencias de diversa índole y a diferentes escalas: individual, grupal, comunitario y social. En Cuba son muchos los esfuerzos que se realizan para que el pueblo tenga una amplia cultura sobre el enfrentamiento a desastres, a fin de reducir al máximo las afectaciones y pérdidas, tanto humanas como económicas. Sin embargo, la novedad del evento que se enfrenta puso a prueba no solo la resiliencia de cada cubano sino la infraestructura sanitaria, económica y social del país para afrontar con eficiencia la situación. Una vez más, el éxito estuvo a cargo de la interdisciplinariedad científica.

Aunque en los últimos años ha habido un incremento de los estudios sobre los desastres que, desde una óptica psicológica, se han realizado en Cuba, la autora no encontró investigaciones dirigidas al enfrentamiento de una pandemia. No obstante, los referentes teóricos de la psicología en situaciones de desastres y de otras disciplinas aplicadas, constituyen fuentes para la elaboración de estrategias de intervención en la comunidad, a la vez que permite un esclarecimiento y afianzamiento de sus presupuestos teóricos. El presente trabajo pretende socializar una experiencia comunitaria en el enfrentamiento a la covid-19, desarrollada en una zona desfavorecida de la provincia Artemisa y sustentada en preceptos teóricos y metodológicos de la psicología social comunitaria, la psicología en situaciones de desastres y la investigación acción-participativa. En un primer momento se presentan los presupuestos teóricos de partida, para luego fundamentar un proyecto de intervención que, sin comprometer la salud de las líderes y los miembros de la comunidad propician el bienestar psicosocial brindando seguridad y apoyo a grupos vulnerables para el enfrentamiento a la Covid-19 y sus consecuencias psicológicas en una comunidad del municipio Caimito en Artemisa.

58 UNESUM-Ciencias. Publicación cuatrimestral. Vol. 5, Año 2021, No. 5 (Septiembre-Diciembre) 


\section{DESARROLLO}

\section{Apuntes teóricos necesarios}

\section{Los desastres}

Existe una variedad de definiciones sobre el término desastre, pues no pocos han sido los investigadores, expertos, organizaciones humanitarias y organismos mundiales que han elaborado conceptualizaciones al respecto. Sin embargo, un análisis de las diferentes definiciones recogidas en la literatura permite apreciar una evolución del término, en cuanto a integralidad se refiere, ya que las más recientes resultan ser más holísticas y abarcadoras, pues hacen alusión al daño humano, material y al medio ambiente (Sauchay, 2009).

La presente investigación toma como referentes la propuesta de Lorenzo, A. (2003) cuando plantea que un desastre:

Constituye un hecho inesperado y de por sí catastrófico, provocando grandes pérdidas humanas y materiales. Los individuos y sus comunidades en mayor o menor medida relacionados con el desastre lo perciben como un evento vital estresante, una especie de situación amenazante y de conflicto, la cual conlleva a una ruptura y modificación del ciclo vital de los damnificados y del equilibrio hombre-entorno en una sociedad concreta.

Al observar las estadísticas y tendencias de las situaciones de desastres en Cuba más frecuentes (Lorenzo, 2006a), es posible establecer un orden jerárquico de estos, de acuerdo a la frecuencia de afectación, siendo los huracanes en sus diferentes formas y clasificaciones los que encabezan la lista. Le siguen las sequías, accidentes del tránsito, inundaciones costeras y movimientos sísmicos, entre otras. Las epidemias, lluvias torrenciales, desprendimientos de tierra y accidentes tóxicos industriales, radiológicos u otros, constituyen las situaciones de desastre que afectan la isla con menor frecuencia. Las acciones que dirige el Estado cubano a la educación y preparación de las personas para el enfrentamiento de desastres, aunque son diversas y desde diferentes sectores y organismos (salud, educación, cultura, medios de comunicación, etc.), también responden a la jerarquía antes mencionada. De manera que la preparación de los individuos, organizaciones laborales y comunidades para el enfrentamiento de pandemias es escasa, teniendo en cuenta que es considerado uno de los desastres menos frecuentes. Sin embargo, no son pocas las consecuencias que puede desencadenar una situación de desastre de este tipo. Así como el resto, puede traer consigo un gran número de problemas para la salud humana y del planeta. En este sentido, puede hablarse de migración, desorden social, hambruna y pérdida de la salud o la vida.

En el orden psicológico, la literatura especializada describe alrededor de 140 reacciones ante los desastres. Las más significativas podrían ser agrupadas en categorías generales como: nerviosismo, inseguridad, ansiedad, angustia, tristeza, shock, colapso narcisístico, duelo, desorganización psíquica, insomnio, entre otras. (Lorenzo, 2003) Refiere Ventura (2011) que aun cuando los desastres no escogen las víctimas, es evidente que no afectan al azar; siempre inciden más en ciertos grupos (niños, adolescente, ancianos y discapacitados) que por sus características son especialmente vulnerables. Según estudios realizados por Navarro (2007) los niños y adolescentes no han construido las defensas suficientes para enfrentar la adversidad, por lo que dependen de la ayuda y el apoyo externo que pueden ofrecer los profesionales capacitados. De no ser identificados y atendidos de manera eficaz tienen mayores riesgos de ser víctimas y de sufrir las pérdidas consecutivas a los desastres. También cabe destacar que en los ancianos son 
comunes las afecciones físicas o emocionales que ocasionan dependencia y sentimientos de minusvalía, todo lo cual disminuye sus capacidades de adaptación y defensa (Ventura, 2012)

Una estrategia de intervención desde un enfoque de apoyo psicosocial basado en la comunidad se sustenta en el reconocimiento de la capacidad de recuperación, resiliencia y reconstrucción y desarrollo futuros de la comunidad afectada. Las intervenciones deben centrarse en abordar las diferentes necesidades de todos los grupos. Se debe proporcionar apoyo psicosocial a los vulnerables, incluidos los niños, las personas mayores con discapacidad, las mujeres embarazadas o madres lactantes. La vuelta a un funcionamiento óptimo debería basarse en la comunidad y potenciarse por medio de actividades sociales. Satisfacer las necesidades espirituales promueve la salud mental y el sentimiento de pertenecer y estar conectado. Es importante fomentar prácticas de sanación comunitarias positivas. Actalliance (2011, p.4) plantea:

La experiencia ha demostrado que las personas que se sienten seguras y vinculadas a otras permanecen tranquilas y esperanzadas. Se demuestra asimismo que quienes tienen acceso a apoyo social, físico, mental, emocional, espiritual y cultural se encuentran en una mejor posición para ayudarse a sí mismos y recibir ayuda de otros.

La pandemia de la covid-19, vivida y sentida como un desastre, puede generar múltiples reacciones psicológicas entre los individuos y sus familias. El aislamiento físico como medida indispensable para detener la propagación del virus interrumpe las conexiones sociales, impone modificaciones a los hábitos y estilos de vida, de trabajo y de relación de las personas, con la aparición de los consecuentes estados de ansiedad y estrés que generan dichos cambios. Aunque pareciera que una estrategia de apoyo psicosocial basado en la comunidad resultaría imposible en estas circunstancias, las autoras la defienden como una vía posible en una comunidad rural, previo diagnóstico psicosocial y mediante el entrenamiento y desarrollo de líderes comunitarias. Ello exige, comprender a la comunidad como categoría psicológica y pensarse estrategias de intervención desde y para la comunidad.

\section{La comunidad como red de apoyo en el enfrentamiento a los desastres}

La concepción de comunidad se ha ido transformando desde posturas más tradicionales en las que prima el elemento territorial, hacia otras en las que se destacan las relaciones, los valores compartidos y el sentido de pertenencia como cuestiones fundamentales. El análisis de varios conceptos permite identificar elementos comunes. A decir de Romero y Muñoz, (s/f), la comunidad se caracteriza por la presencia de:

- Intereses y objetivos comunes. La acción social vinculada a la satisfacción de necesidades, solución de problemas cotidianos y el desempeño de funciones sociales relevantes.

- Interacción social sostenida, cooperación y participación social en un contexto determinado (territorial, escolar, eclesial, virtual, laboral, entre otros).

- Sentido psicológico de comunidad expresado en el sentimiento o conciencia de similitud, presencia de costumbres, valores, estilos de vida, tradiciones, símbolos compartidos.

En lo que respecta a la flexibilidad con que podamos operar con una definición pertinente para el trabajo de campo, se evidencia que en el imaginario popular la noción encuentra enlace directo con el barrio, con la localidad donde cohabitan las personas. Sin embargo, tiende a moverse a ejes más cercanos que la contextualizan, como son los grupos de amigos, vecinos y edificaciones, pues aunque se identifique con lo local, se concreta en redes y espacios, que son, en definitiva, los ámbitos en que se hace tangible para las personas.

El sentido de comunidad es el sentimiento de ser parte de una red de apoyo, de una estructura social que te represente, lo que remite a integración y sentido de pertenencia. También se

60 UNESUM-Ciencias. Publicación cuatrimestral. Vol. 5, Año 2021, No. 5 (Septiembre-Diciembre) 
necesitan percepciones de similitud e interdependencias, así como la voluntad de mantener estas últimas. La fusión entre participación y sentido de comunidad constituyen célula estructural y funcional de una comunidad, en tanto espacio de encuentro e integración de subjetividades individuales y sociales, fusión de imprescindible referencia para estimular prácticas transformadoras desde el protagonismo de actores comunitarios. La intervención comunitaria está estrechamente vinculada al proceso de diagnóstico y evaluación de necesidades. Por lo general las necesidades han sido estudiadas desde dos referentes teóricos: uno a partir de sus características objetivas y otra, en cómo son percibidas por los sujetos, así vemos como "la necesidad deviene en un criterio valorativo del sentido subjetivo de un momento histórico dado y de los cambios sociales que le definen; estos últimos parcialmente entendidos si son ajenos al espacio de lo que es necesario”. Tovar, M. A. (1994) La intervención se realiza teniendo como propósito la comunidad en su conjunto, un problema identificado por esta o un grupo poblacional específico, pero siempre debe caracterizarse por su carácter participativo, en tanto se realiza con la implicación activa de los actores. Debe partir del diagnóstico de necesidades percibidas o sentidas por los mismos y no inferidas o normadas desde posiciones externas de autoridad, a su vez resulta imprescindible la identificación de problemas desde la perspectiva de los sujetos, estimulando su participación en la solución de los mismos, se trata de una intervención que, a diferencia de otras, no se centra en las debilidades sino en las potencialidades de los sujetos como actores de desarrollo. (Moras, 2016)

\section{Aspectos metodológicos}

Desde la Psicología Social Comunitaria se presentan diferentes alternativas metodológicas para el trabajo en la comunidad (Tovar, 2005), entre las cuales resalta la Investigación Acción Participativa. Ello implica un proceso colectivo de aprendizaje, con el cual la comunidad se responsabiliza y asume su control. Supone una comunicación horizontal entre los participantes y una retroalimentación sistemática.

Esta metodología implica el avance progresivo de fases, que sin ser estrictas sino flexibles, guían el proceso en la consecución de los objetivos del trabajo:

1. Montaje institucional y metodología de la investigación participativa.

2. Estudio preliminar y provisional de la zona y población. Retroalimentación a la comunidad.

3. Análisis crítico de la situación de pandemia en la comunidad, las necesidades de sus miembros y las posibilidades de satisfacción desde dentro. Retroalimentación de los avances de la actividad de análisis de problemas.

4. Programación y ejecución de un plan de acción para brindar apoyo psicológico desde y para la comunidad.

En cada caso se emplean como técnicas fundamentales para la recogida de información: la entrevista individual, la observación participante y la encuesta.

Para la investigación que se presenta, todas las acciones están dirigidas al diagnóstico de los grupos vulnerables dentro de la comunidad, la identificación de sus necesidades y estados emocionales asociados a la pandemia para favorecer el empoderamiento de la comunidad en la búsqueda de nuevas formas de conectarse (desde el aislamiento) y brindar, desde adentro, apoyo psicosocial, con la participación de todos los actores sociales. 


\section{Principales resultados}

Siguiendo esta metodología, se logra una caracterización sociopsicológica de la comunidad, cumpliendo así con las dos primeras fases del proceso interventivo. Se identifican grupos vulnerables y se comprometen actores sociales indispensables para el apoyo psicosocial. Constituye este el primer paso del proyecto comunitario "Desde mi Casa", que, desde un enfoque psicosocial, apuesta por el bienestar físico y psicológico de la comunidad en tiempos de pandemia.

\section{Caracterización sociodemográfica}

La comunidad estudiada está compuesta por 50 núcleos familiares y un total de 136 personas. De ellas, 30 (22.05\%) son adultos mayores que en 12 de los 50 núcleos familiares (24\%) viven solos o en pareja. Asimismo, conviven 21 niños (escolares y de la primera infancia) lo que representa el $15.4 \%$ y 18 adolescentes y jóvenes (13.23\%). Analizando estas cifras, se puede percibir que el 50.7 \% de la población que habita en la comunidad (69 personas) constituyen grupos de riesgo ante situaciones de desastre.

También resultan de interés 1 embarazada y 6 trabajadores del sector de la salud (enfermeras y médicos) unido a 4 estudiantes de medicina que se mantuvieron realizando pesquisajes activos durante el período de la investigación.

\section{Evaluación de necesidades}

\section{Necesidad de seguridad y protección}

Todos los miembros de la comunidad evidencian en su comportamiento esta necesidad, asociada fundamentalmente a la salud. Asimismo, se expresa una confianza absoluta en la medicina cubana y las posibilidades de sanación en el contexto cubano, hecho que, en algunos casos disminuye la percepción de riesgo. Algunos miembros de la comunidad, aunque verbalizan la preocupación por su salud y la de sus familiares, asumen conductas riesgosas y exponen a la comunidad. Entre las causas fundamentales de ese comportamiento se encuentra la escasa percepción de riesgo y el depositar la responsabilidad de su salud en una agencia externa a sí. El sentimiento de vulnerabilidad y la vivencia de desastre por la ruptura del ciclo vital y la tangible posibilidad de la muerte quedan explícitas en sus comportamientos, demandantes de apoyo psicológico.

Necesidad económica y material

La necesidad económica muestra su preponderancia en la vida social desde los inicios de la misma, pero adquiere formas específicas en función de los contextos históricos particulares. En el caso de la comunidad estudiada la necesidad económica está marcada por la vivencia de una situación de desastre que genera escasez de productos para la satisfacción de necesidades básicas, en un escenario caracterizado por la vivencia de desigualdad en la sociedad, el acceso al consumo como criterio diferenciador y símbolo de status y prestigio, incertidumbre tanto para los que viven con 
más comodidad como para los que menos, insatisfacción con el salario y las condiciones de vida, baja productividad, cambios en el modelo de sociedad ideal y bienestar, etc. Esta situación, que se hace más evidente en las comunidades de lugar ubicadas en territorios poco favorecidos, provoca que las necesidades económicas repercutan en los materiales, manifestándose desde la carencia debido a: problemas constructivos de las viviendas y espacios públicos; insalubridad y falta de higiene en calles y espacios públicos; dificultades para el acceso a recursos que satisfacen necesidades básicas como alimentos, productos de aseo. Inexistencia de ofertas para las personas vulnerables, que no deben salir de casa por el riesgo que representa para la salud, condicionando la existencia de conflictos intrapsíquicos del tipo ganar-perder.

Necesidad de socialización, afiliación, comunicación

El hombre es un ser social, que, sin la interacción social, no puede nunca desarrollar en él los atributos y características que se han desarrollado como resultado de la evolución sistemática de toda la humanidad. Esta necesidad resulta relevante para el desarrollo de la comunidad, en tanto está en su base, explica la importancia de formar y transformar la colectividad como medio para el crecimiento personal y social. Esta necesidad adquiere expresiones específicas marcadas por la vivencia de situación de desastre y el llamamiento constante desde las autoridades sanitarias a mantener el distanciamiento físico y el aislamiento social. Constituye una necesidad recurrente, actuando desde la carencia en los grupos poblacionales estudiados:

-Los adolescentes demandan un cambio en el estilo de comunicación con los padres y cuya carencia se manifiesta en problemas de interacción entre padre e hijos. El conflicto adultoadolescente generado por la divergencia de opiniones de adultos y adolescentes, en cuanto a los derechos y deberes de estos últimos se acentúa en muchos de los casos estudiados por la mayor permanencia en el hogar, el mantenimiento de una actitud autoritaria de los padres hacia el cumplimiento de las medidas sanitarias y la ausencia de posibilidades para el intercambio con coetáneos.

- Los adultos mayores que viven solos experimentan mayor insatisfacción de esta necesidad y la demandan con mayor énfasis como una vía para contrarrestar los sentimientos de angustia, incertidumbre y tristeza que les genera la pandemia. Se exponen a una sobresaturación de información que resulta dañina para un enfrentamiento saludable de la situación. Muestran síntomas de ansiedad y angustia por la imposibilidad de mantener contacto físico con coetáneos, vecinos y familiares que viven en el exterior del país. Desde esta propuesta se legitiman nuevas formas de participación. Se construyen aprendizajes colectivos desde la distancia física, apoyados en el sentido psicológico de comunidad, que se refuerza ante la vivencia de una situación de desastre.

-Los niños escolares vivencian la situación a modo de vacaciones, por lo que experimentan la necesidad de afiliación y socialización con mayor intensidad. Ello se corresponde con un mal manejo por parte de los padres, quienes emplean estilos comunicativos inadecuados, exacerbando en muchos casos, la ansiedad que experimentan los niños.

Necesidad de recreación y esparcimiento:

Esta necesidad limita su satisfacción al espacio personal y/o familiar. Respecto al primero, los objetos de satisfacción fundamentales se asocian a la realización de actividades tales como ver la televisión y escuchar música). Aun cuando esto constituye una generalidad, se manifiestan ciertas pautas de consumo que diferencian a determinados grupos poblacionales y comunidades respecto a otras, tal es el caso de: 
- El grupo poblacional de niños, tal como se espera de acuerdo con las regularidades de la edad, consume materiales audiovisuales de tipo Infantiles y Dibujos animados. Mientras que el resto de los grupos poblacionales y comunidades en general se caracterizan por el consumo de películas cuyos géneros oscilan fundamentalmente entre la comedia, la ciencia ficción y el policiaco; así como la visualización de series; y en el caso particular de la población femenina se aprecia también una marcada inclinación por el consumo de novelas. Los grupos poblacionales de adolescentes ven limitadas sus opciones preferidas de satisfacción como la práctica de deportes (fundamentalmente futbol) y la salida a fiestas y discotecas con los amigos (principales objetos de satisfacción de esta necesidad).

\section{Sentido Psicológico y Participación}

El sentido psicológico de comunidad constituye una fortaleza en la comunidad estudiada, en la cual se asienta la estrategia de intervención que pretende brindar apoyo psicológico desde y para la comunidad. Se aprecia una mayor riqueza en la dimensión vertical -individual-, en tanto resalta el mantenimiento de tradiciones, rituales, identificación de símbolos, prácticas y costumbres propias de la comunidad. No obstante, la dimensión horizontal -interpersonalfavorece la búsqueda de nuevas formas de hacer y participar, en tanto, se reconocen y se establecen lazos necesarios entre los miembros de la comunidad para el ejercicio activo, en calidad de decisores, de las actividades y acciones de la vida social de la comunidad. La comunidad asigna roles a sus miembros y estos los asumen en beneficio de todos, de manera que el desarrollo de líderes comunitarios en el enfrentamiento a la pandemia tuvo una elevada aceptación y un marcado éxito para las acciones de apoyo psicológico a grupos vulnerables dentro de la comunidad.

\section{Acciones comunitarias de apoyo psicosocial en tiempos de pandemia.}

\section{Capacitación a líderes comunitarias}

Las líderes comunitarias emergen de la comunidad, roles asumidos por dos jóvenes carismáticas, entusiastas, creativas, responsables y con elevada capacidad movilizativa dentro de la comunidad. Precisaron intercambios con autoridades de salud (médico de la familia, estudiantes de medicina de la comunidad) para conocer a profundidad las medidas higiénico-sanitarias que debían garantizar durante sus acciones de apoyo psicosocial. A modo de talleres, charlas e intercambios, actualizaron semanalmente el cumplimiento de las medidas y convocaron a los miembros de la comunidad a realizar carteles e iniciativas que promovieran conductas saludables. Asimismo, implicaron a personas con comportamientos riesgosos en la realización de plegables con mensajes positivos de salud. También se capacitaron en el reconocimiento de necesidades de apoyo psicológico en personas vulnerables.

Orientación a padres y madres de niños escolares y de la primera infancia

Intercambios sobre las principales angustias y preocupaciones de los padres en el manejo del tiempo de los niños. Convocatoria a pensar actividades que ocupara el tiempo de los niños saludablemente y de las que resultara un obsequio para alguien de la comunidad. De estas acciones derivaron iniciativas interesantes que agradecieron los padres, los niños y adultos mayores de la comunidad. Se revirtió en mayor permanencia de los niños en sus casas, equilibrio entre actividades de estudio, juego y audiovisuales a la vez que se fortaleció el sentido psicológico de comunidad en su dimensión interpersonal. Los adultos mayores beneficiados (sorprendidos con los obsequios de los niños) redujeron los sentimientos de soledad y tristeza. Apoyo psicosocial a adultos mayores

64 UNESUM-Ciencias. Publicación cuatrimestral. Vol. 5, Año 2021, No. 5 (Septiembre-Diciembre) 
Unido a las acciones individuales de pesquisa y acompañamiento psicológico que realizaban líderes comunitarias y otros actores sociales como los estudiantes de medicina, psicóloga y médico de la familia, se les convocaba a mantener la realización de ejercicios físicos dentro de la casa. También confeccionaron y regalaron a los niños de la comunidad un "amuleto de la esperanza”, para mantenerse en casa seguros esperanzados de que pronto podrían regresar a sus aulas, compartir con coetáneos y socializar como habitualmente hacían.

Implicación de adolescentes y jóvenes en tareas de apoyo psicológico

Se creaban mensajes de salud desde el vocabulario y la cotidianidad de este grupo etario. Creación de espacios virtuales (mediante WhatsApp) para intercambiar sentimientos, preocupaciones y estilos personales en el afrontamiento de la pandemia. Ello permitió la vivencia de acompañamiento a la vez que fortaleció la toma de decisiones responsables. De esta forma fueron surgiendo espacios diferentes de satisfacción a las necesidades de recreación y esparcimiento. La convergencia de adolescentes y jóvenes en espacios comunes (desde la distancia) permitió momentos de reflexión sobre los estilos de comunicación padre-hijo y la búsqueda de nuevas formas de relación.

\section{CONCLUSIONES}

La declaración de una pandemia por la OMS y la confirmación en Cuba de personas con el Sarscov-2 condujeron a la toma de múltiples medidas a nivel nacional para evitar la propagación del virus. La presente da muestras de que esta situación fue percibida como catastrófica en una comunidad de Caimito, pues conllevó a la ruptura del ciclo vital de la mayoría de las personas. Se modificaron estilos y hábitos de vida, de trabajo y de relación con la aparición de los consecuentes estados de ansiedad y estrés que generan dichos cambios. El trabajo de campo que acompaña la investigación se realiza desde el paradigma de la Investigación Acción Participativa, como estrategia metodológica que resulta idónea por propiciar el protagonismo de los sujetos en el proceso investigativo y su empoderamiento como actor de desarrollo en prácticas de transformación, especialmente en una situación de desastre que implica la transformación colectiva para el beneficio de todos. Desde esta propuesta se intentan revertir las vulnerabilidades de los grupos poblacionales en fortalezas mediante el desarrollo de líderes comunitarias que favorecieron el acompañamiento y apoyo psicológico a los convivientes.

\section{REFERENCIAS BIBLIOGRÁFICAS}

Actalliance (2011) Apoyo psicosocial basado en la comunidad. Principios rectores. Federación Internacional de Sociedades de la Cruz Roja y de la Media Luna Roja. Consultado en: www.cruzrojacolombiana.org

Lorenzo, A. (2003). Apoyo psicológico en desastres. Gerencia de desastres en Cuba. (pp. 10-16) Centro de Información y Documentación del Centro Latinoamericano de Medicina de Desastres (CLAMED) . Kingston, Jamaica: CARDIN

Lorenzo, A. (2006). Reflexiones sobre la evolución del quehacer psicológico en el tema de emergencias y desastres. Análisis de la experiencia en Cuba. Cuadernos de crisis, 5(2), 7-37.

Moras, P. E. (2016) Participación y consumo cultural de la adolescencia. Ponencia presentada en VIII Encuentro Internacional de Estudiantes de Psicología. Universidad de La Habana. Cuba

Navarro, V. R. (2007). Manual para la preparación comunitaria en situaciones de desastres. Cienfuegos, Cuba: Ediciones Damují.

Organización Panamericana de la Salud. (2013). Guía práctica de Salud Mental en Situaciones de Desastres. Washington, D.C.

Romero, M. y Muñoz, M. (s/f) Comunidad y desarrollo comunitario: aspectos teóricos y metodológicos. La Habana: FLACSO.

(C) Universidad Estatal del Sur de Manabí. Jipijapa, Ecuador. 
Sauchay, L. (2009). Reflexiones sobre definiciones de desastre. En Salud y Desastres. Experiencias cubanas Tomo I (pp. 271-279). La Habana, Cuba: Editorial Ciencias Médicas ECIMED.

Tovar, M. A. (1994). Investigación comunitaria. Una contribución desde la psicología social. Revista Cubana de Psicología, 11 (1), 29-34.

Tovar, M. A. (2005) Concepción metodológica del estudio psicosocial de la comunidad. En Fuentes, M., Vasallo, N., Álvarez, L. y Pañellas, D. (2005) Psicología Social II. Parte 2. Selección de lecturas. La Habana: Editorial Félix Varela.

Ventura R. (2012) Trastornos psicosociales en desastres. Temas para entrenamiento. ECIMED. La Habana, Cuba: Editorial de Ciencias Médicas

66 UNESUM-Ciencias. Publicación cuatrimestral. Vol. 5, Año 2021, No. 5 (Septiembre-Diciembre) 